\section{SEA LEVEL RISE HISTORY AND CONSEQUENCES}

\author{
Edited by Bruce C. Douglas, Michael S. Kearney \\ and Stephen P. Leatherman \\ Foreword by John Knauss \\ Academic Press, Vol. 75, International Geophysical Series \\ 232 pp. ISBN 0122213459
}

\author{
Review by Orrin H. Pilkey \\ Duke University, Durham, North Carolina USA
}

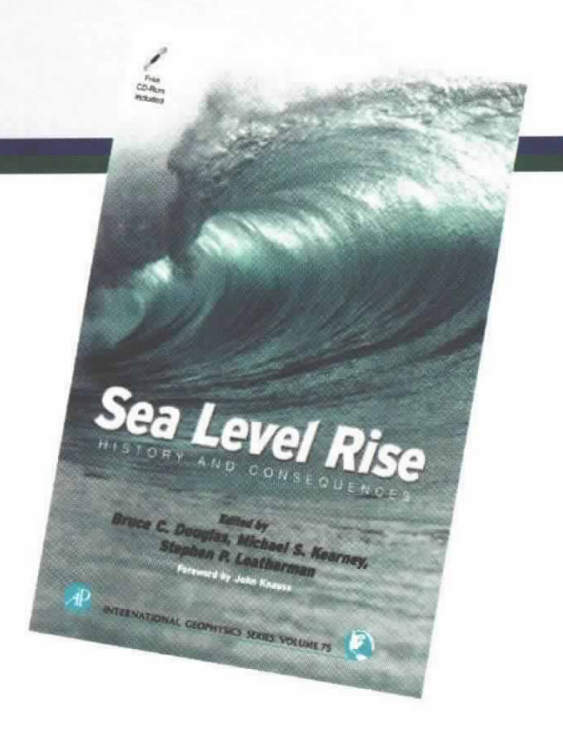

This propitious volume arrives at a time of increasing concern about the state of our shorelines. Generally written at a level for advanced undergraduates, this well edited, multi-author volume includes chapters by some of the biggest players in the specialty, including Vivien Gornitz, W.R. Peltier and Stephen Leatherman. Sea Level Rise is the best available volume for the nonspecialist and specialist alike to come up to speed on this important topic.

Sea level has been rising, more or less, for 18,000 years. The critical part of relative sea level change to human society however, is the rise of the last century and what this implies for future generations. A significant and growing proportion of the world's population lives close to the sea; perhaps 100 million of us live within a meter of sea level. Starting with the midnineteenth century, the volume of water in the sea began to increase and sea level has been rising in midlatitudes at 2 millimeters per year ever since. John Knauss in his thoughtful foreword notes that this rise began before global warming began. Clearly, the global and local components of sea level change at a given location are many and complex.

Four of the 8 chapters are concerned either with the technology of measurement of relative sea level rise or the history of sea level on several scales ranging from Late Holocene variations (Michael Kearney) to decadal variability (W. Sturges and B.G. Hong). The tide gauge record, currently our most important and ubiquitous source of sea level change information, is discussed by Bruce Douglas and satellite altimetry, a remarkable new technology and global addition to sea level change tools, is covered by Steven Nerem and Gary Mitchum.

In the most quantitative chapter, Peltier makes the case that global isostatic adjustment can explain most wayward carbon-14 sea level dates. Where viscoelastic theory fails to explain regional sea level history, high tectonic activity may be masking reality. Gornitz discusses the sea level rise impact of human induced changes in the hydrologic cycle on land. Runoff from extracted ground water, paved surfaces and deforestation add to the sea level rise and water storage in reservoirs while infiltration of water from reservoirs and irrigation reduces it. Gornitz estimates that the net effect of all these human induced changes is a lowering of the level of the sea, of the order of 1 millimeter per year.

Additional chapters include an introduction to the subject by Bruce Douglas and a Stephen Leatherman contribution on the all-important sociologic and economic consequences of sea level rise.

In my view (some of book's authors may disagree) Sea Level Rise makes a strong case that we have a weak case when it comes to quantifying most of the important questions about sea level rise. Great strides have 
been made in sea level change measurement but longer records are needed to sort out noise, and data points are still missing from large geographic areas. We don't know for certain why the sea level is rising, because many of the component parts of sea level rise remain in the educated guess category. From this it follows that we don't know with any conviction or reasonable certainty what sea level will do in the future; at what rate it will rise and for how long and whether or not it will accelerate. And of course, these are the questions for which society most needs the answer, if we are to coexist peacefully with the world's shorelines.

On the other hand, Sea Level Rise makes it clear that huge progress in understanding this phenomenon has been made in the last decade and that we can expect more of the same in the first decade of the new millennium.

My biggest problem with this book is the unquestioning acceptance of the Bruun Rule in both the Douglas and Leatherman chapters. The now outdated rule, which predicts the relationship between sea level rise and shoreline retreat, has been long abandoned by most coastal scientists because its theoretical underpinning is non-existent. Since this is virtually the only equation in the arsenal of coastal managers to predict shoreline retreat, it has unfortunately found widespread but misplaced application. In general, predicted erosion rates using the equation are significantly too low. A hearty Bruun rule endorsement in this book does not help the case for future coastal management in the context of a rising sea level.

Included with the volume is a CD ROM containing monthly mean tide gauge data from a number of sites and a fascinating animated presentation of global sea surface temperature anomalies.

Bruun Rule aside, this is an excellent volume, a must for the library of all that seek to manage our coasts or to learn about one of the most important ramifications of the greenhouse effect.

\section{Q.0.0.0 Investing in the Future}

Are you an active, experienced scientist or engineer, with the maturity and imagination to develop innovative programs in basic research through advanced development? Would you like to become a part of a team that maintains world-class superiority in Navy and Marine Corps needs?

The Office of Naval Research (ONR), headquartered in Arlington, Virginia, coordinates, executes, and promotes the science and technology programs of the U.S. Navy and Marine Corps through universities, government laboratories, and nonprofit and for-profit organizations. If you're eager to inspire and guide innovation that will enhance our knowledge base and provide technology-based options for future Navy and Marine Corps capabilities, ONR may have an opportunity for you!

\section{APPLY TODAY}

To obtain information on GS/I 3 - I 5 Program Officers, IPA's and SES employment opportunities in the areas of basic physical and biological sciences through engineering disciplines (both full-time or temporary) at ONR, please visit our website at http://www.onr.navy.mil/.

ONR's greatest asset is our cadre of outstanding personnel.

\section{OFFICE OF NAVAL RESEARCH}

An Equal Opportunity Employer

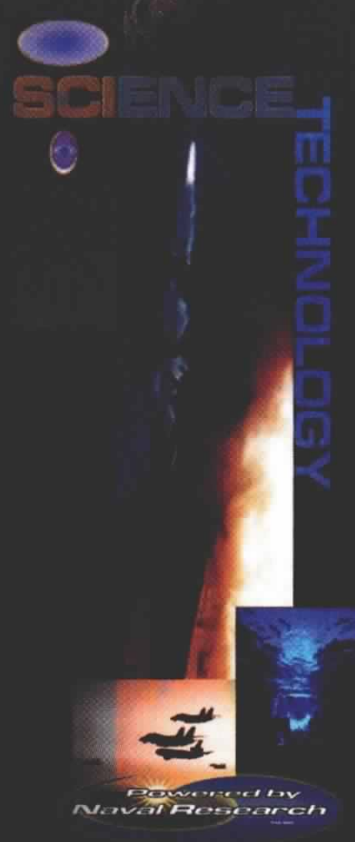

